\title{
An unconscious elderly woman with an abnormal electrocardiogram
}

Farhad Huwez, Martin Edwards

An 83-year-old woman was found unconscious on the street by the police. She was brought to her local casualty department. There was no sign of alcohol intoxication and no evidence of focal neurological deficit. Her initial electrocardiogram (ECG) is shown below.

Department of Medicine, East Glamorgan General Hospital, Church Village,

Nr Pontypridd, Mid-Glamorgan CF38 1AB, Wales, UK F Huwez

M Edwards

\section{Correspondence to} Dr F Huwez, Scottish

Cardiopulmonary Trans-

plant Centre, University Department of Cardiac Surgery, The Royal

Infirmary, Glasgow

G31 2ER, Scotland, UK

Accepted 12 December 1995

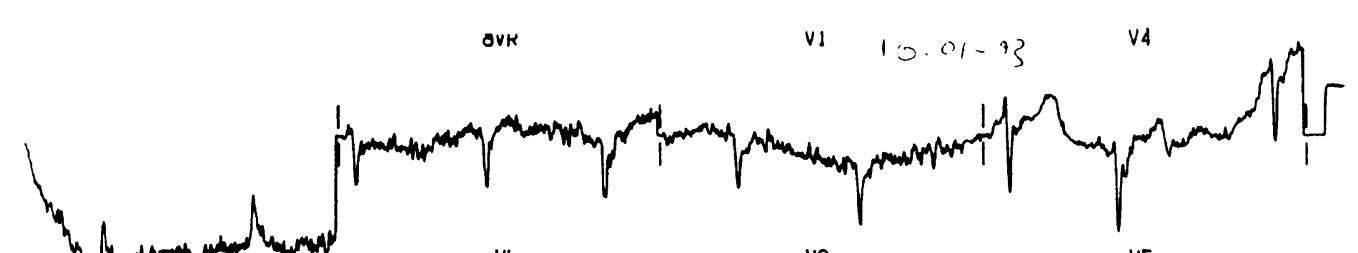

oVL

v2

v5

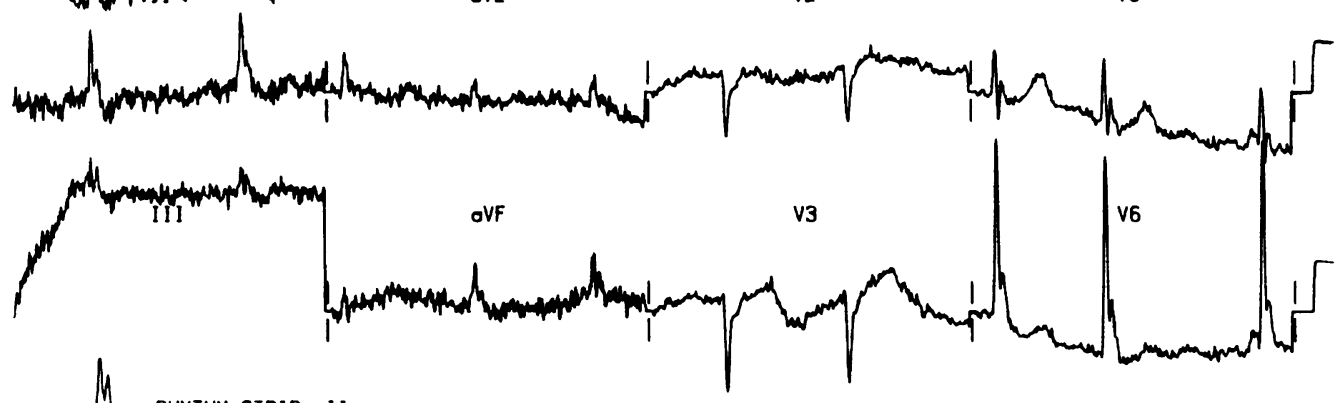

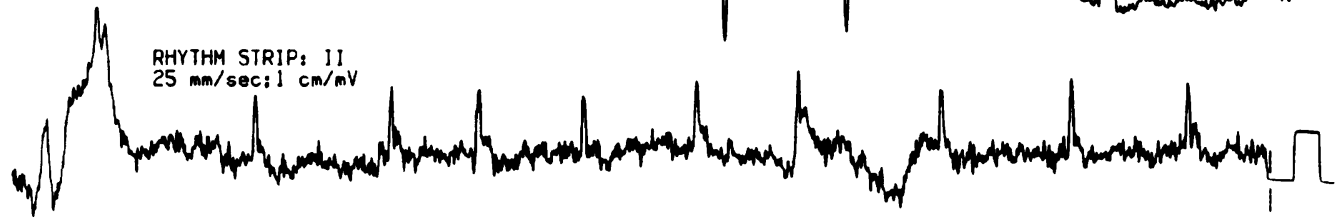

OC $00000-0000$

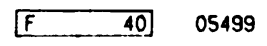

Figure Electrocardiogram

\section{Questions}

1 What is the most likely diagnosis?

2 What treatment would you start?

3 Describe two ECG abnormalities. 


\begin{abstract}
Answers
QUESTION 1

Hypothermia. At the casualty department, this elderly woman was unresponsive and her extremities were very cold and cyanotic. Her tympanic membrane temperature on arrival was $27.8^{\circ} \mathrm{C}$.
\end{abstract}

\section{QUESTION 2}

She was rewarmed gradually with space blankets, given warm intravenous fluids, cefotaxime and nasal oxygen. About 10 hours later both her temperature and ECG had returned to normal. Biochemical and haematological screen were unremarkable. Her chest X-ray did not show evidence of chest infection. Thyroid functions were normal. More information became available and she was found to be a spinster and living alone. After full recovery from her hypothermia, a computed tomography scan of the head showed marked cerebral atrophy without focal lesion. Senile dementia was diagnosed and her care was transferred to the psychogeriatric ward.

\section{QUESTION 3}

The ECG demonstrates marked $\mathrm{J}$ waves and muscular tremor. The J wave or camel hump sign is the most striking feature on the ECG of patients with hypothermia. It is a slowly inscribed extra deflection between the QRS complex and the early part of the ST segment. The $\mathrm{J}$ wave is upright and more prominent in leads facing the left ventricle, and it increases its amplitude as body temperature falls. ${ }^{1}$ The J wave may become so marked that it may distort the QRS complex, simulating right bundle branch block or intraventricular conduction defect. The mechanism for the appearance of the $\mathrm{J}$ wave on the ECG in hypothermia is not known. It has been suggested to be the result of anoxia, a response to injury, delayed ventricular depolarization, or early repolarization occuring in one part before delayed depolarization is completed in another part of the ventricle. ${ }^{2}$ Other ECG features of hypothermia include slowing of the sinus rate, prolongation of the PR and QTc intervals, and muscular tremor. ${ }^{1}$ The latter may be present without clinical shivering or chills. All these

1 Harumi K. Hypothermia. In: Macfarlane PW, Lawrie TDV, eds. Comprehensive electrocardiology. Oxford: Pergamon Press, 1989; pp 685-8.

2 Trevino A, Razi BM, Beller B, Antonio S. The characteristic electrocardiogram of accidental hypothermia. Arch Intern Med 1971; 127: 470-3

3 Duckworth WC, Cooper BC. Accidental hypothermia in Bantu. S Afr Med f 1964; 38: 295-8.

\section{Electrocardiographic features of} hypothermia

- the most marked features of the resting ECG is the $J$ wave which is a slowly inscribed extra deflection between the QRS complex and the ST segment

- J waves are not diagnostic of hypothermia and may occur in cerebral injuries and myocardial ischaemia

- J waves may be confused with intraventricular conduction defects. Other ECG features of hypothermia include muscular tremor, sinus bradycardia, prolonged PR- and QTc-intervals

- ECG changes of hypothermia are reversible

ECG features are reversible with rewarming. ${ }^{3}$ It should be noted that $\mathrm{J}$ waves are not diagnostic of hypothermia as they may be seen in some patients with cerebral injuries and in others with myocardial ischaemia. ${ }^{1}$ Cardiovascular complications are common, including dysrrhythmias, conductive defects, and hypotension. For these reasons, cardiac and haemodynamic monitoring are integral parts of the treatment strategy in hypothermic patients. Other complications of hypothermia include hypoventilation and apnoea in severe cases, chest infections (often the clinical signs are scanty), gastric dilatation, pancreatitis, hyperglycaemia (reduced insulin sensitivity), impaired liver function, oliguria, sludging, and multiple infarcts of the myocardium, limbs or viscera. ${ }^{4}$

Hypothermia in winter months is not uncommon, particularly in the elderly. A recent study by Hislop et al suggested that hypothermia is probably responsible for over 4000 hospital admissions and over 1000 deaths per annum..$^{5}$ Its recognition is vital as it is treatable and its ECG changes should not be confused with conduction abnormalities.

\section{Final diagnosis}

Hypothermia.

Keywords: hypothermia, electrocardiogram

4 Wollner L, Spalding JMK. The autonomic nervous system In: Brocklehurst IC, ed. The textbook of geriatric medicine and gerontology, 3rd edn. Edinburgh: Churchill Livingstone gerontology, 3rd 3

5 Hislop LJ, Wyatt JP, McNaughton GW, et al. Urban Hislop LJ, Wyatt JP, McNaughton GW, et al. Urban
hypothermia in West of Scotland. BMf 1995; 311: 725-6. 